\title{
Epidural analgesia in parturients with previous spinal irradiation
}

Amy Beth R. Hilton MD,

Ellen M. Lockhart MD,

Donald H. Penning MD MSC

Purpose: To present two successful cases of labour analgesia in patients who had been treated with radiation to the lumbar spine for neuroblastomas and to discuss the considerations when planning the anaesthetic management of these patients.

Clinical Features: We recently encountered two primigravidas requesting labour analgesia, both of whom were noted to have very thin backs with prominent spinous processes and obvious scoliosis. In both patients, the epidural space was easily identified and very shallow. Successful labour analgesia was achieved in both patients, one with a combined spinal epidural technique and the other with an epidural catheter.

Conclusion: Craniospinal irradiation is known to have long-term effects on exposed nervous tissue, bone, and blood vessels. While a larger experience is necessary to demonstrate safety of regional anaesthesia in parturients following previous spinal irradiation, we provide reports of two successful cases.

Objectif : Présenter deux cas réussis d'analgésie pendant le travail chez deux patientes qui avaient reçu de la radiothérapie à la colonne lombaire pour des neuroblastomes et discuter des préoccupations qui entourent la planification de l'anesthésie dans ce cas.

Aspects cliniques : Nous avons rencontré récemment deux primigestes qui désiraient de l'analgésie pendant le travail ; on a noté chez ces deux femmes une paroi dorsale mince et des apophyses épineuses saillantes ainsi qu'une scoliose évidente. Chez les deux patientes, l'espace péridural était facilement identifié et peu profond. L'analgésie pendant le travail a été réussie chez les deux patientes en utilisant, pour l'une, une technique rachidienne péridurale combinée et, pour l'autre, un cathéter péridural.

Conclusion : Lirradiation craniorachidienne est connue pour avoir des effets prolongés sur le tissu nerveux, les os et les vaisseaux sanguins touchés. Quoiqu'une plus vaste expérience soit nécessaire pour démontrer la sécurité de l'anesthésie régionale chez des parturientes qui ont connu auparavant une irradiation rachidienne, nous rapportons ici deux cas couronnés de succès.

From the Division of Women's Anesthesia, Department of Anesthesiology, Duke University Medical Center, Box 3094, Durham, North Carolina 27710

Address correspondence to: Dr. Ellen Moseley Lockhart. Phone: 919-681-3345; Fax: 919-681-7022; E-mail: lockh005@mc.duke.edu Accepted for publication June 17, 1998. 


\section{Case Reports}

\section{Patient I}

An 18 yr old primigravida presented for consultation at $35 \mathrm{wk}$ gestation. Past medical history included a Stage IV neuroblastoma, first diagnosed at two years of age, and treated by surgical excision, radiation, and chemotherapy which included adriamycin. Over the years she had several chemotherapy and radiation related complications, including adriamycin cardiomyopathy, a benign but extensive ganglioneuroma, renal artery thrombosis necessitating nephrectomy, and a neurogenic bladder. An abdominal computed tomography performed one year before our consultation showed stable residual periaortic ganglioneuroma that encased the coeliac artery, superior mesenteric artery, and aorta. The tumour displaced the inferior vena cava to the right and the portal and superior mesenteric vein superiorly. Echocardiography at $14 \mathrm{wk}$ gestation demonstrated global hypokinesis and an ejection fraction of $35-45 \%$, which was unchanged from studies done before her pregnancy. She had one episode of congestive heart failure during the second trimester of the pregnancy concurrent with a urinary tract infection and required digoxin $0.5 \mathrm{mg} \mathrm{qD}$ and furosemide $30 \mathrm{mg} \mathrm{qD}$.

On physical examination she was a thin woman in late pregnancy who walked about the labour floor without dyspnea. She was $158 \mathrm{~cm}$ tall and weighed 70 $\mathrm{kg}$. She had minimal ankle oedema. Her lungs were clear but she had a grade II/VI systolic murmur at the left upper sternal border. Her back was thin and her spinous processes were prominent and easily palpated. She had an obvious lumbar scoliosis, which she had been told was a result of her radiation therapy. Sensation was diminished over $S_{1-5}$ bilaterally and she had slightly decreased strength in her right hamstring, biceps, triceps, and hand grasp.

After a literature search failed to reveal reports regarding labour analgesia in patients with previous spinal irradiation, we discussed our hypothetical concerns with the patient, which we derived from the known permanent and deleterious effects of therapeutic radiation on bone and nervous tissue. We were concerned that her scoliosis could make access to the epidural or intrathecal space technically difficult, and that the tissue planes might be scarred or obliterated by post-radiation fibrosis. She was informed of the increased risk of failed or incomplete block and of postdural puncture headache. The theoretically increased risk of local anaesthetic neurotoxicity in compromised neural tissue was also discussed. These risks were weighed against the advantage of decreasing cardiac workload by providing pain relief. Following this discussion the patient agreed to epidural or intrathecal catheter placement and central venous and arterial pressure monitoring as needed. Over her lifetime she had undergone numerous spinal taps and vascular access procedures. Venous access was always difficult and the patient requested that a central line be placed for intra-and post-partum use.

She presented at 39 wk gestation with oligohydramnios and was admitted for induction of labour. The risks and benefits of anaesthesia and invasive monitoring were once again reviewed with the patient. Initially, we planned to place a central line via the right internal jugular vein for venous access and monitoring. However, the vein was difficult to access and could not be catheterized. Instead, a peripheral intravenous line was placed after several attempts and an oxytocin infusion was titrated to initiate and maintain labour. Invasive arterial pressure monitoring was deferred because of the patient's stable course. When the patient was in active labour, she was given an intravenous bolus of lactated Ringer's lactate solution and an epidural catheter was placed easily at the $\mathrm{L}_{3-4}$ interspace with a $17 \mathrm{G}$ Tuohy needle with the patient in the sitting position. Loss-of-resistance to saline occurred at a depth of only $3 \mathrm{~cm}$. Labour analgesia was induced with two $3 \mathrm{~mL}$ boluses of lidocaine $1.5 \%$ with epinephrine $1: 200,000$. This produced a gradual onset of sensory blockade without any change in heart rate or sensorium. The patient obtained good pain relief with a sensory level of $T_{8}$ on the right and $T_{10}$ on the left. When the level regressed, $15 \mathrm{~mL}$ bupivacaine $0.125 \%$ in $5 \mathrm{ml}$ increments over ten minutes and an infusion of bupivacaine $0.08 \%$ with $2 \mu \mathrm{g} \cdot \mathrm{mL}^{-1}$ fentanyl was started at $10 \mathrm{~mL} \cdot \mathrm{hr}^{-1}$. After $6.5 \mathrm{hr}$ the patient began to experience increased discomfort. The infusion was complete and then replaced with ropivacaine $0.1 \%$ with 2.5 $\mu \mathrm{g} \cdot \mathrm{mL}^{-1}$ of fentanyl and epinephrine $1: 200,000$ at the preference of the covering anesthesiologist. A bolus of $5 \mathrm{~mL}$ and a $10 \mathrm{~mL} \cdot \mathrm{hr}^{-1}$ continuous infusion of this solution produced good labour analgesia. After forceps-assisted vaginal delivery three hours later, the epidural infusion was reduced in increments of $2 \mathrm{~mL}$ per hour over six hours and then turned off to allow gradual resolution of vasodilatation and redistribution of fluid after delivery. The patient did not develop a post-dural puncture headache, and had no back pain, or worsening of neurological deficit. Mother and baby did well and both were discharged home within $72 \mathrm{hr}$.

\section{Patient 2}

A 32 yr old primigravida presented in labour at term and requested labour analgesia. Her cervix was dilated 
to $8 \mathrm{~cm}$. She reported that she had received radiation therapy for a neuroblastoma resected in infancy and had required laparotomy and lysis of adhesions for small bowel obstruction as a teenager. She was $155 \mathrm{~cm}$ tall and weighed $55 \mathrm{~kg}$. She had a known scoliosis and lower limb length discrepancy, but had not experienced any back pain during pregnancy. Her back was very thin, and the spinous processes were easily palpated. Due to the advanced labour and degree of discomfort, a combined spinal-epidural technique was performed in the right lateral decubitus position. The epidural space was entered at the $\mathrm{L}_{3-4}$ interspace $3 \mathrm{~cm}$ from the skin. A $26 \mathrm{G}$ Gertie Marx spinal needle was introduced through the $17 \mathrm{G}$ Tuohy needle. There was good flow of CSF via the Gertie-Marx needle and 2.5 $\mathrm{mg}$ bupivacaine with $20 \mu \mathrm{g}$ fentanyl in a volume of 1.4 $\mathrm{mL}$ were injected through the spinal needle. The spinal needle was withdrawn intact and an epidural catheter was easily inserted.

The patient had relief from the majority of her labour pain, but complained of back pain, possibly due to the occiput posterior presentation of the fetus. When severe back pain persisted after $20 \mathrm{~min}$, the epidural catheter was dosed in $5 \mathrm{~mL}$ increments with methylparaben-free, bicarbonated 2-chloroprocaine $2 \%$ with epinephrine $1: 200,000$, after a $3 \mathrm{~mL}$ test dose of this solution produced no change in heart rate or sensory blockade. Chloroprocaine was chosen as it was felt that delivery would be imminent and a rapid onset of analgesia was desired. In total, $14 \mathrm{~mL} \mathrm{2-}$ chloroprocaine and one $\mathrm{mL}(50 \mu \mathrm{g})$ fentanyl were required to provide good pain relief and a $T_{8}-S_{5}$ bilatcral block. It was subjectively felt that the resistance to epidural injection was greater than usual. After the last increment of $4 \mathrm{ml} 2$-chloroprocaine and $50 \mu \mathrm{g}$ fentanyl were given, the site was inspected again for catheter migration. The catheter had not moved, but there was a pocket under the transparent dressing containing 3-4 mL of clear fluid. No fluid returned with aspiration of the epidural catheter during dosing or after this leakage was noted. The patient delivered vaginally $90 \mathrm{~min}$ after the final catheter dose without any further supplementation. The patient had no back pain during or after delivery and did not develop postdural puncture headache. Mother and baby did well and both were discharged home within $48 \mathrm{hr}$.

\section{Discussion}

As the field of paediatric oncology progresses, more and more children are surviving childhood cancers and living normal lives. We are beginning to see these survivors on the labour ward. To date, there are no data on the long-term effects of radiation on the epidural space or the success or failure of epidural analgesia or anaesthesia in patients who received therapeutic craniospinal irradiation. Diffuse white matter injury and/or atrophy of CNS tissue occurs in up to $50 \%$ of these patients. ${ }^{1}$ Micro-and macroangiopathy, as well as telangectasia can develop within the irradiated field. ${ }^{1}$ Fatty replacement of bone marrow, osteoradionecrosis, ${ }^{1}$ and osteoporosis have been reported, along with associated kyphosis, ${ }^{2}$ or stress fractures. ${ }^{3}$ Furthermore, spinal shortening and generalized growth retardation have been noted in children receiving craniospinal radiation, due in part to pituitary damage and growth hormone insufficiency. ${ }^{4}$ Our two patients had considerable scoliosis in the radiation field and both appeared to have some atrophy of the soft tissue overlying the spine. Because their backs were so easily palpated, the scoliosis did not make needle placement technically difficult, but it does suggest disruption of vertebral growth; one wonders whether the development of the epidural space is similarly affected. Neither of our patients had visible telangiectasias. The risk of bleeding from puncturing abnormal blood vessels is a theoretical concern but telangiectasias usually develop in the radiated white matter and are usually small $(<5 \mathrm{~mm})$ and are rarely associated with clinically important bleeding. ${ }^{1}$ In our patients the epidural space was shallow but easily identified. Neither patient had a patchy or unilateral block. The first patient required a smaller volume of local anaesthetic than the average patient to produce adequate analgesia. In the second patient the epidural space, while easily identified with loss-of-resistance to saline, felt "tight" when the catheter was injected. Although we did not test the fluid under the dressing for characteristics of CSF, it seems more likely that local anaesthetic tracked back along the catheter, since we could not aspirate fluid via the catheter and she did not develop post-dural puncture headache. It is unclear whether the partial failure of the intrathecal dose in the second patient was related to any anatomical or physiological anomalies produced by the spinal irradiation. It may have simply been a technical failure or breakthrough pain due to the OP presentation. The patient did not request additional pain relief in the $90 \mathrm{~min}$ between epidural catheter dosing and delivery. This suggests that either the 2-chloroprocaine had a prolonged duration of action in this patient or that the residual effects of the intrathecal fentanyl and bupivacaine provided sufficient analgesia. The onset time and rate of resolution of sensory blockade with both intrathecal and epidural local anaesthetics may have been delayed by tissue fibrosis.

In conclusion, while greater experience is necessary to demonstrate the safety of regional anaesthesia in 
parturients following previous spinal irradiation, we provide reports of two successful cases. In these patients, one should look for scoliosis and/or kyphosis in the irradiated field and expect the epidural space to be shallow relative to the skin. The epidural space may be "tight", possibly increasing the cephalad spread of local anaesthetic per unit of volume, so we recommend giving small increments of volume slowly. We cannot comment on the chance of success for a combined spinal-epidural technique or single-shot spinal, except to say that our second patient did not report any complications which might have been associated with the combined technique. Should such a patient require Caesarean section, our experience suggests a spinal or an epidural technique can be successful.

Successful labour analgesia, as in our two patients, does not preclude neurological complications in subsequent patients. Standard practice with such patients should include a thorough neurological evaluation to identify potential areas of compromised neural tissue that may be susceptible to further injury. The benefits of effective labour analgesia and the risks of painful labour should be weighed against the still unclear degree of risk of spinal or epidural analgesia/anaesthesia in patients who have had craniospinal irradiation.

\section{References}

1 Rabin BM, Meyer JR, Berlin JW, Marymount MH, Palka PS, Russell EJ. Radiation-induced changes in the central nervous system and head and neck. Radiographics 1996; 16: 1055-72.

2 Burgers JMV, Staalman CR, De Kraker J, Oldenburger $F$, Delemarre JFM, van der Eijken JW. Vertebral abnormalities after treatment for Ewing sarcoma. Med Pediatr Oncol 1997; 28: 54-8.

3 Peh WCG, Khong PL, Sham JST, Ho Wr, Yeung HWD. Sacral and pubic insufficiency fractures after irradiation of gynaecological malignancies. Clin Oncol 1995; 7 : 117-22.

4 Kiltie AE, Lashford LS, Gattamaneni HR. Survival and late effects in medulloblastoma patients treated with craniospinal irradiation under three years old. Med Pediatr Oncol 1997; 28: 348-54. 